\title{
Histological changes of the rat liver after administration of imatinib mesylate:an experimental study
}

\author{
Luma Ibrahim Khalel Al-Allaf, Hafidh Al-Ashoo \\ Department of Anatomy, College of Medicine, University of Mosul, Mosul, Iraq. \\ Correspondence: Lumaallaf1971@yahoo.com
}

Received

Accepted

14.1.2014

4.3.2014

\section{ABSTRACT}

Objectives: This study aims to determine the histological changes of the liver of rats after administration of a low dose or a clinically relevant high dose of Imatinib mesylate for one month in comparison to control ones.

Study setting and design: This experimental study was performed over a period of four months starting from the $10^{\text {th }}$ march 2013 to the $10^{\text {th }}$ July 2013 and was conducted on male Albino rats purchased from Animal Houses of both Mosul Medical College, and Veterinary College, University of Mosul, Mosul, Northern Iraq.

Methods: The first experiment includes40- 45 days aged rats who administered orally

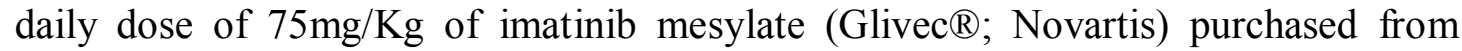
IBN-SENA Teaching Hospital, Mosul and bought from some private pharmacies for 30 days with age matched control who administered distilled water. The second experiment includes $40-45$ days aged rats who administered daily dose of $200 \mathrm{mg} / \mathrm{Kg}$ orally)with age matched control who administered distilled water . Liver of rats from each experimental group were obtained. The tissues were embedded in paraffin and stained with hematoxylin-eosin and periodic acid schiff stain.

Results: The histological examination of the liver tissues of groups receiving imatinib at doses of $75 \mathrm{mg} / \mathrm{kg}$ or $200 \mathrm{mg} / \mathrm{kg}$ on daily for 30 days duration showed different degrees of various histological changes of damage when compared with the control group . Male rats administered with $75 \mathrm{mg} / \mathrm{kg}$ of imatinib resulted moderate degree of several histological changes. The most striking feature is disruption in radial arrangement around central vein, sinusoidal dilatation, and hepatocytes with eosinophilic cytoplasm. Perivenular inflammatory cells, accumulation of inflammatory cells. Loss of cellular outline, and loss of euchromatin of the hepatocytes .Light microscopic examination of sections obtained from liver tissues of groups receiving imatinib at dose of $200 \mathrm{mg} / \mathrm{kg}$ revealed similar changes, however, these changes were more pronounced in comparison to those in low dose group.

Conclusion: Imatinib causes hepatotoxicity even in low dose group $(75 \mathrm{mg} / \mathrm{kg}$, however, it has a dose dependant effect but to some extent. Appropriate protective measures must be applied with anticancer treatment for improving liver function.

Keywords: Imatinib mesylate, chronic myelogenous leukemia, hepatotoxicity.

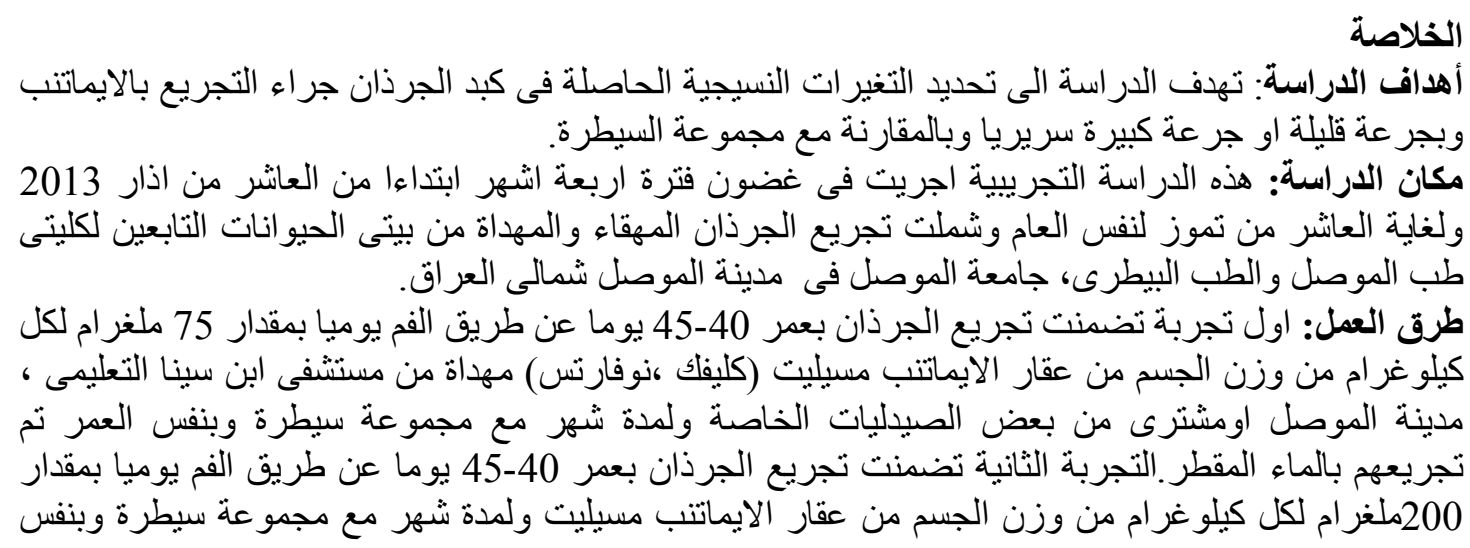


العمر تم تجريعهم بالماء المقطر.تم اخذ الكبد وطمره بالبار افين وصبغه بعد ذلك باهيماتوكسلين ايوسين وصبغة

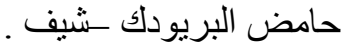

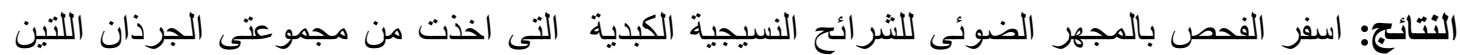

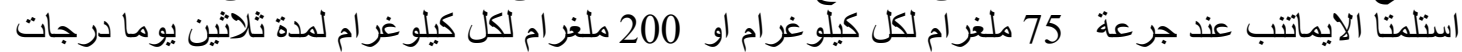

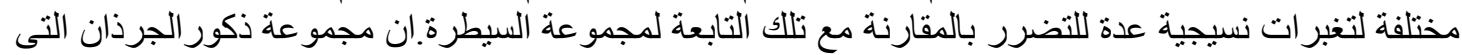

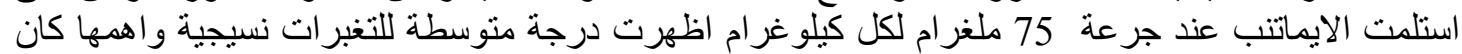

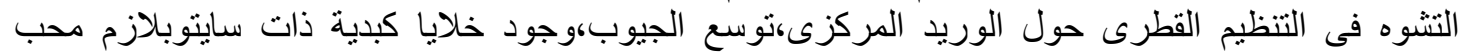

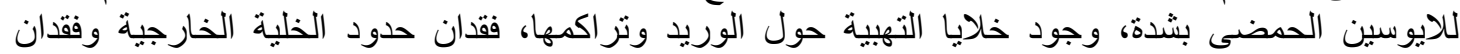

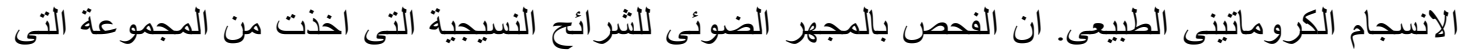

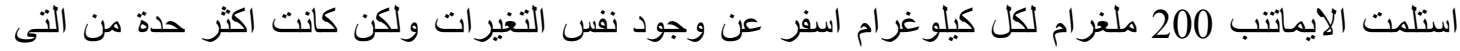
استلمت الجر عة القليلة.

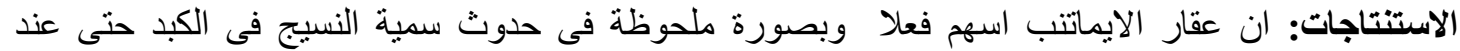

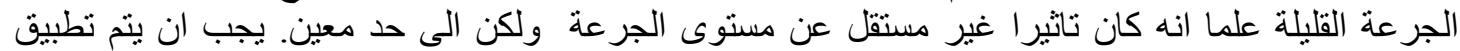

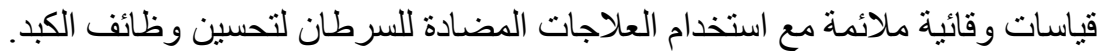

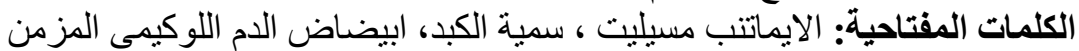

$C$ hronic myelogenous leukemia 1 (CML) is a myelo- proliferative disorder characterized by the presence of translocation $\mathrm{t}(9 ; 22) \quad(\mathrm{q} 34 ; \mathrm{q} 11)$ which generates the Philadelphia $(\mathrm{Ph})$ chromosome and the associated fusion gene (Abelson murine leukemia) (BCR-ABL) ${ }^{1}$.

BCR-ABL1 encodes the chimeric protein BCR-ABL1 which has deregulated tyrosine kinase activity and leads to increased cellular proliferation, resistance to apoptosis and genetic instability and it is at the center of CML pathogenesis, as attested by mouse models which replicate the disease ${ }^{2}$. CML, once considered a fatal disease, is now essentially a chronic disorder, and most patients can enjoy long-term survival. This history of success has been the result of development of tyrosine kinase inhibitors (TKIs), compounds which suppress the abnormal tyrosine kinase (TK) activity of the BCR-ABL1 protein $^{3}$.

Chemotherapy involves the use of chemical agents to stop the growth and eliminate cancer cells even at distant sites from the origin of primary tumor. However, it does not distinguish between a cancer and normal cells, and eliminates not only the fast-growing cancer cells but also other fast-growing cells in the body, including, hair and blood cells ${ }^{4}$.

Imatinib (Gleevec $\AA$ or Glivec $\AA$ Novartis, NJ), is a selective, rationally designed, c-KIT and Bcr-Abl tyrosine kinase inhibitor, approved for the treatment of chronic myelogenous leukemia $(\mathrm{CML})^{5}$, gastrointestinal stromal tumors $(\text { GIST) })^{6,7}$, and unresectable GIST ${ }^{8}$.

Currently imatinib is the treatment of choice for the management of the chronic and accelerated phases of CML with an overall survival rate of $89 \%$ after 5 years ${ }^{6,7}$. Besides the BCRABL kinase, imatinib also inhibits the expression of c-Kit tyrosine kinase receptor in the gastrointestinal tract which is involved in the pathogenesis of gastrointestinal stromal tumors (GIST) ${ }^{8}$. In addition, imatinib inhibits the platelet derived growth factor (PDGF) receptor ${ }^{9}$. which may allow further therapeutic applications including dermatofibrosarcoma protuberans $^{10}$, glioblastoma ${ }^{11}$, and noncancer related pathologies like rheumatoid arthritis ${ }^{12}$ and atherosclerosis $^{13}$.

Imatinib undergoes P450 mediated metabolism mainly via CYP3A4 and CYP3A5, and CYP1A2, CYP2D6, CYP2C9 and CYP2C19 which play a minor role ${ }^{14}$. Imatinib and metabolites are excreted in the bile and only 
around $5 \%$ is excreted unchanged in urine $^{15,16}$. The main adverse effects include severe neutropenia and thrombocytopenia, oedema, fluid retention, nausea, mild diarrhoea, skin rashes, arthralgia, myalgia, bone pain, acute renal failure and hepatotoxicity $^{17,18}$.

Hepatotoxicity has been observed in $5 \%$ of CML patients which show cytolytic hepatitis (including spotty and piecemeal necrosis), hepatic necrosis, and acute hepatitis. In spite of the fact that hepatotoxicity resolved after imatinib discontinuation and steroids administration, in some patients, the hepatic condition further deteriorated leading to fatal liver failure $^{19}$. Histopathological findings revealed severe necrosis, cellular canalicular cholestasis, submassive acute hepatic necrosis and multiacinar hepatocellular necrosis ${ }^{20,21}$. The majority of TKIs approved to date are reported to induce hepatic injury. Several studies reporting imatinibinduced hepatic lesions describe various types of changes in hepatocyte morphology. However, It is apparent that many important issues regarding the potential adverse effects of Imatinib on the liver need further clarification. This study aims to evaluate the histopathological changes that occur in liver of rats administered different regimens of imatinib mesylate (either low dose or high dose imatinib mesylate for one month duration) in comparison to the control ones.

\section{Materials and Methods}

This experimental study was performed over a period of four months starting from the 10th march 2013 to the 10th July 2013 and was conducted on male Albino rats purchased from Animal Houses of both Mosul Medical College, and Veterinary College, university of Mosul, Mosul, Northern Iraq.
Throughout the investigations the rats were housed under controlled normal environmental laboratory conditions and animal facility and were kept in an air-conditioned room with 12-hours light and dark cycles, where the temperature $(22 \pm 2 \circ \mathrm{C})$ and relative humidity $(65-70 \%)$ were kept constant. They were local breaded and put individually in Animal House plastic cages $^{22}$.Animals were let to acclimatize for a week before any experiment was performed $^{23}$, and provided with free access of water ad libitum and pelleted stanrdized food ${ }^{24}$. The experiments were performed during the light portion $^{25}$.

Experimental design and procedures

Mean bodyweight of all rats was 70-110 gm. The first experiment includes 40-45 days aged rats who administered daily dose of $75 \mathrm{mg} / \mathrm{Kg}$ of imatinib mesylate (Glivec $\AA$ Novartis) purchased from IBN-SENA Teaching Hospital or bought from some private pharmacies and were dissolved in distilled water and administered orally by gavage with 24 gage needle for 30 days $(n=8)$ with age matched control who administered distilled water following the same protocol applied to imatinib group $(n=4)$.

The second experiment includes 40- 45 days aged rats who administered daily dose of $200 \mathrm{mg} / \mathrm{Kg}$ orally by gavage with 24 gage needle for 30 days $(n=8)$ with age matched control who administered distilled water following the same protocol applied to imatinib group $(n=4)$.

Imatinib doses selected were intended to be in the range of those used in clinical treatment regimens ${ }^{26}$ $(400-800 \mathrm{mg} / \mathrm{d}$ or $340-590 \mathrm{mg} / \mathrm{m} 2$ based on a weight of $70 \mathrm{~kg}$ ) dose surface area adjusted to body-weight, $f \times \mathrm{mg} / \mathrm{kg}=\mathrm{mg} / \mathrm{m} 2$, where $f$ is a constant equal to 6.0 in rats $^{27}$.Each animal was observed for overt signs of toxicity. The animals were firmly 
restrained (the animal was grasped by the loose skin of the neck and back) to immobilize the head and maintained in an upright (vertical) position. The gavage needle was passed through the side of the mouth, followed the roof of the mouth, and advanced into the esophagus toward the stomach. After the needle was passed to the correct length, imatinib was injected ${ }^{28}$.

\section{Study termination procedures} Animals in each experiment were euthanized with ether ${ }^{22,29} 24 \mathrm{~h}$ after the final dose was given at laboratory of postgraduate studies of Department of Anatomy, Mosul College of Medicine, University of Mosul.

Tissue and organs collection: Liver portions of rats from each experimental group were obtained using longitudinal thoracoabdominal incision and they were immersed in Nacl solution $0.9 \%$ for few seconds in order to get rid of superficial blood. The liver was excised and examined macroscopically.

Preparation of histological sections Liver were fixed in $10 \%$ Neutral buffered formalin ${ }^{30}$, the tissues were embedded in paraffin (Merck, Germany) and stained with Harris hematoxylin-eosin (Scarlau, Spain) and periodic acid schiff stain (PAS). The evaluation was blinded to treatment and any data. The tissue of hepatic samples were grossed and transferred into cassettes and processed as follows: (1) - Two consecutive changes of solution of $10 \%$ Neutral buffered formalin $1 \mathrm{~h}$ and $1.5 \mathrm{~h}$; (2)85\% Ethyl alcohol (Thomas baker,(chemicals), limited, UK)- $1.5 \mathrm{~h}$; (3) 95\% alcohol $1.5 \mathrm{~h}$; (4) $100 \%$ Alcohol - three consecutive changes of $1.5 \mathrm{~h}$ each; (5) xylene (Thomas baker, (chemicals), limited, UK)- three consecutive changes of $1.5 \mathrm{~h}$ each; and (6) paraffin bath at $55^{\circ} \mathrm{C}$ - two changes of $1.5 \mathrm{~h}$ each. Upon completion, the tissues were placed in $1.5 \times 2 \mathrm{~cm}$ moulds lined with molten paraffin wax at $65^{\circ} \mathrm{C}$. The mould was transferred to a cold plate at $-5^{\circ} \mathrm{C}$, the tissue adjusted to the desired orientation and the cassette base placed on top of the mould, filled with molten wax and let to solidify for $1 \mathrm{~h}$, removed and then stored at $-20^{\circ} \mathrm{C}$ until sectioning. The frozen embedded wax blocks were sectioned at 3-5 micron thickness using Reichert-Jung microtom (Austria), placed on frosted glass slides and dried overnight at $37^{\circ} \mathrm{C}$. Prior to modified Harris Haematoxylin and Eosin staining and periodic acid schiff stain (PAS) for general liver structure and periodic acid schiff (PAS) to demonstrate the glycogen deposition in hepatocytes respectively, the samples were washed in xylene twice ( 3 min each), hydrated in five sequential changes of alcohol $100 \%, 100 \%, 95 \%, 80 \%$ and $70 \%$ for 3 min each, rinsed with water for $3 \mathrm{~min}$ and stained. Finally, the stained slides were dehydrated in three sequential 1min changes of alcohol $70 \%, 80 \%$ and $95 \%$ and two changes of alcohol $100 \%$ for three minutes each. The sections were then dried and mounted onto the clean glass slides and labeled ${ }^{31,32}$.

\section{Histopathological analysis}

Histopathology changes were observed for changes in toxicokinetic assessment including sinusoidal congestion, loss of cellular outline and lobular architecture, nuclear changes, and fatty changes $^{31}$. On the other hand, disruption in radial arrangement around central vein, sinusoidal dilatation, hepatocytes with eosinophilic cytoplasm, hydropic degeneration (cytoplasmic vacuolization and swelling of hepatocyte), and loss of the glycogen deposition in hepatocytes. These changes were grouped based on two main criteria: vascular changes including vessel congestion, sinusoidal dilatation, extravasation of red blood cells and hematoma formation; and 
necrotic changes including necrosis, fibrosis, nuclear changes, abscesses and cell regeneration ${ }^{33}$.

The morphological changes were assessed semi-quantitatively to assess the extent of the histopathological changes, blind by an independent assessor and graded as follows: No change - 0 (no distinguishable change, $0 \%$ ); mild change - 1 (initiation of changes, up to $30 \%$ ); moderate change - 2 (patent changes, 31-60\%); severe change - 3 (wide spread changes, 61-100\%) for each criterion. Maximum score is noted as $9^{34}$.

\section{Photography}

All sections were visualized in Bright field Olympus microscope(Japan). Photomicrographs of representative changes were taken using digital camera (Optika, Italy, HD 1080, resolution 8.0 Mega pixels) attached using planapochromatic objectives. The magnifications of photomicrograph will be indicated with the legends for the photograph.

\section{Results}

The histopathology assessment in liver was performed blindly for all groups. At necropsy, no obvious tissue abnormalities were noted in the liver of any animal. This study revealed that the light microscopic examination of the liver sections obtained from of the control group showed a normal appearance of the liver cells which appeared as normal large polygonal cells with prominent round nuclei and eosinophilic cytoplasm, and few spaced hepatic sinusoids arranged inbetween the hepatic cords with fine arrangement of Kupffer cells (Figure 1,2).

The histological examination of the liver tissues of groups receiving imatinib at doses of 75 or $200 \mathrm{mg} / \mathrm{kg}$ daily for 30 days showed different degrees of various histological changes of damage when compared with the baseline-control group. Male rats administered with $75 \mathrm{mg} / \mathrm{kg}$ of imatinib resulted moderate degree of several histological changes (Table 1).

The most striking feature is disruption in radial arrangement around central vein, sinusoidal dilatation, and hepatocytes with eosinophilic cytoplasm (Figure 3).

Perivenular inflammatory cells, accumulation of inflammatory cells were shown in Figures 4,5,6.

Loss of cellular outline, and loss of euchromatin of the hepatocytes were noticed in sections obtained from the liver tissues of group receiving imatinib at doses of $75 \mathrm{mg} / \mathrm{kg}$ (Figures $5,6,7)$.

Light microscopic examination of sections obtained from liver tissues of groups receiving imatinib at dose of $200 \mathrm{mg} / \mathrm{kg}$ revealed similar changes; however, these changes were more pronounced in comparison to those in low dose group (Figures $8,9,10,11,12,13)$.

Moreover, high dose group showed various features of nuclear alterations of hepatocytes including anisocytosis (Figure 9), presence of dense apoptotic nuclei (Figure 12).In addition, swelling of hepatocytes were also noticed (Figure 9,13).

Feathery degeneration was shown obviously especially in sections obtained from liver tissues of groups receiving imatinib at dose of $200 \mathrm{mg} / \mathrm{kg}$ (Figure 11).

Microscopic damage score for each group was determined and results were given in Table 1.

Figures 14,15 shows the decreased amount of glycogen in the sections obtained from the liver tissues of groups receiving imatinib at doses of 75 or $200 \mathrm{mg} / \mathrm{kg}$ respectively. 
Table 1. Comparison of the effect of imatinib on microscopic structure in liver in all groups

\begin{tabular}{|c|c|c|c|}
\hline Parameter & Control Group & Low dose Group & High dose Group \\
\hline Microscopic damage & 0.6 & 4.9 & 5.1 \\
\hline
\end{tabular}
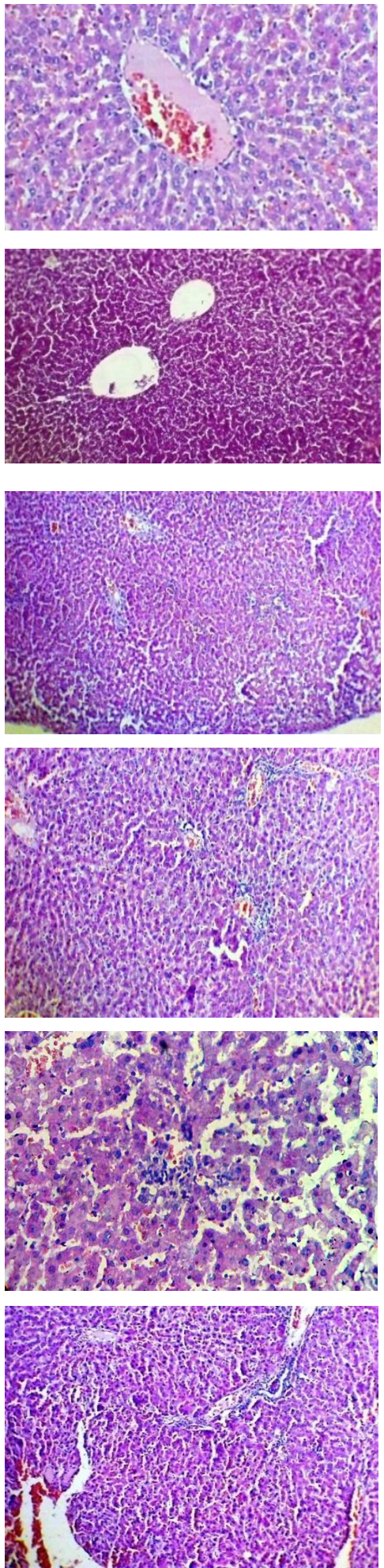

Figure 1. A photomicrograph of a section obtained from the liver of rat of control group with normal histological appearance $(\mathrm{H} \& \mathrm{E} \times 400)$.

Figure 2. A photomicrograph of section obtained from the liver of rat of control group showed The PAS-positive reaction shows a magenta staining where glycogen is present within hepatocytes (PAS $\times 250)$.

Figure 3. A photomicrograph of section obtained from the liver of rat treated with low dose of imatinib showed disruption of radial arrangement of hepatic cords, dilation of sinusoid, presence of esinophilic stained hepatocytes $(\mathrm{H} \& \mathrm{E} \times 250)$.

Figure 4. A photomicrograph of section obtained from the liver of rat treated with low dose of imatinib showed disruption of radial arrangement of hepatic cords , presence of few perivenular inflammatory cells (H\&E $\times 250$ ).

Figure 5. A photomicrograph of section obtained from the liver of rat treated with low dose of imatinib showed disruption of radial arrangement of hepatic cords , dilated sinusoids, accumulation of inflammatory cells and esinophilic hepatocytes with loss of euchromatin and cellular outline $(\mathrm{H} \& \mathrm{E} \times 400)$.

Figure 6. A photomicrograph of section obtained from the liver of rat treated with low dose of imatinib showed disruption of radial arrangement of hepatic cords , dilated sinusoids, accumulation of inflammatory cells in perivenular area and esinophilic hepatocytes with loss of euchromatin $(\mathrm{H} \& \mathrm{E} \times 250)$. 

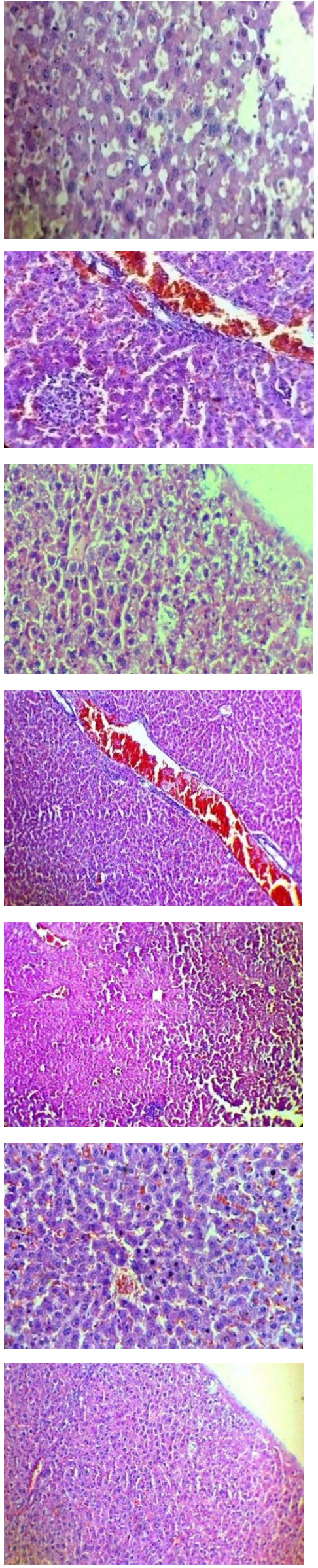

Figure 7. A photomicrograph of section obtained from the liver of rat treated with low dose of imatinib showed disruption of radial arrangement of hepatic cords, obliterated sinusoids, and esinophilic hepatocytes with loss of cellular outline $(\mathrm{H} \& \mathrm{E} \times 400)$.

Figure 8. A photomicrograph of section obtained from the liver of rat treated with high dose of imatinib showed congested portal vein and sinusoids, presence of accumulated inflammatory cells with esinophilic stained hepatocytes $(\mathrm{H} \& \mathrm{E} \times 400)$.

Figure 9. A photomicrograph of section obtained from the liver of rat treated with high dose of imatinib showed swelling of hepatocytes with degeneration and loss of euchromatin, area of dissolution of hepatic cords was noticed $(\mathrm{H} \& \mathrm{E} \times 600)$.

Figure 10. A photomicrograph of section obtained from the liver of rat treated with high dose of imatinib showed congested portal vein, dilation of sinusoid, presence of esinophilic stained hepatocytes $(\mathrm{H} \& \mathrm{E} \times 250)$.

Figure 11. A photomicrograph of section obtained from the liver of rat treated with high dose of imatinib showed disruption of radial arrangement of hepatic cords, esinophilic hepatocytes with loss of euchromatin and cellular outline, and feathery degeneration $(\mathrm{H} \& \mathrm{E} \times 250)$.

Figure 12. A photomicrograph of section obtained from the liver of rat treated with high dose of imatinib showed esinophilic hepatocytes with loss of euchromatin and cellular outline, hepatocytes with apoptotic nuclei are also seen(H\&E $\times 400)$.

Figure 13. A photomicrograph of section obtained from the liver of rat treated with high dose of imatinib showed esinophilic hepatocytes with loss of euchromatin and cellular outline, swelling of hepatocytes with anisocytosis are also noticed $(H \& E \times 400)$. 

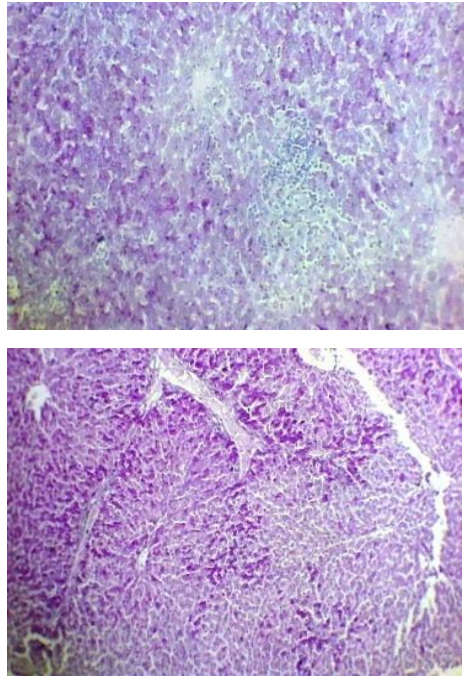

Figure 14. A photomicrograph of section obtained from the liver of rat treated with low dose of imatinib showed decreasing in the glycogen amount(PAS $\times 400)$.

Figure 15. A photomicrograph of section obtained from the liver of rat treated with high dose of imatinib showed decreasing in the glycogen amount $(\mathrm{PAS} \times 250)$.

\section{Discussion}

Drugs targeting tumor-specific pathways are believed to be more effective than conventional chemotherapeutic drugs, which tend to affect rapidly dividing cells in both normal and cancerous tissues. Targeted small molecule drugs have revolutionized treatment of CML over the last decade ${ }^{35}$. The introduction of small-molecule TKIs in clinical oncology has transformed the treatment of certain forms of cancers. However, their use has been found to be associated with serious toxic effects on a number of vital organs including the liver ${ }^{35,36}$.

This study revealed many histopathological abnormalities in the liver. These findings are in accordance with that of Cohen et $\mathrm{al}^{36}$, who reported presence of hepatotoxicity after 2 weeks of imatinib administration in dogs. The histological assessment revealed mild focal hepatocellular necrosis, single cell bile duct necrosis and bile duct hyperplasia (associated with peribiliary fibrosis) $^{36}$. However, Seggara et $\mathrm{al}^{31}$ revealed the histological findings in mice with lesser degree of toxicity which may be anticipated since they used a single oral dose of imatinib (100 $\mathrm{mg} / \mathrm{kg}$ ); while the greater toxicity observed in the reported cases may be contributed by imatinib accumulation due to the multiple dosage administration $^{31,36}$. On the other hand ,in humans, signs of liver dysfunction were found in CML patients with grade 3.

In addition, fatal liver failure occurred in several cases ${ }^{21,37}$. The pathogenic mechanisms of imatinib-induced hepatotoxicity are unknown ${ }^{31}$. Research on the pathogenic mechanisms of imatinib-induced hepatotoxicity suggests that toxicity may be related to the P450 mediated metabolic pathway or idiosyncratic reactions in susceptible individuals 38.A study which was done by Sherif et $\mathrm{al}^{29}$ showed comparable results were obtained with the rat's liver following treatment with imatinib ,he suggested that the histopathological investigation showed hydropic changes and attributed that to the increase in NO production (reflected in the total NOx content level). Augmentation of cardiotoxicity following treatment with imatinib with arsenic might be attributed to imatinib- induced PDGF receptor and c-Ab1 blockade ${ }^{29}$.

On the other hand, chemotherapeutic agents such as cisplatin, doxorubicin, and 5-FU cause direct hepatic toxicity including inflammatory cells forming 
granulomatous lesions and periportal fibrosis and apoptosis ${ }^{4}$.

It has been suggested that Doxorubicin has been shown to induce accumulation of inflammatory cells ${ }^{39}$, associated with increased activities of tissue aminotransferases, lactate dehydrogenase and alkaline phosphatase, indicating hepatic damage via induction of apoptosis and generation of reactive oxygen radicals $^{40,41}$.

A recent article suggested that activation of endoplasmic reticulum stress after imatinib is a cause of imatinib-induced cardiomyopathy ${ }^{42,43}$. Any pathological state that leads to increased production and/or ineffective scavenging of reactive oxygen species may play a crucial role in determining tissue injury ${ }^{44,45}$. The administration of cyclophosphamide damages the liver $^{46,47}$. Tissue damage due to cyclophosphamide might be alleviated due to the antioxidant property and membrane stabilizing property of melatonin ${ }^{48,49,50}$. It is known that eosinophilic-stained cells show the starting irreversible damage in the tissue $^{32}$. On the other hand, there were degenerative changes as swelling of hepatocytes (reversible damage) in the rat treated with methotraxate , and that is attributed to oxidative stress ${ }^{32,51}$. This study showed many histopathological abnormalities in the liver including inflammatory infiltration, hyperplasia, periportal fibrosis, marked disruption of hepatic cords and dilated blood sinusoids. Many hepatocytes showed karyomegaly and pyknotic nuclei indicating apoptosis. Cell death can result from naturally occurring apoptosis(physiological apoptosis) or from irreparable cell injury (pathological apoptosis) as described by Farber in $1994^{52}$. Apoptosis is a common feature of hepatotoxicity induced by many chemicals; it may precede necrosis, as in the hepatotoxicity induced by thioacetamide $^{4}$, or it may occur concurrently with necrosis as in hepatotoxicity associated with acetaminophen $^{31}$.This study showed that the hepatotoxic effect of imatinib was more pronounced in high dose group in comparison with that in low dose, these finding is in accordance with that of Kerkela et al in $2006^{31}$ and Sook Han et al in 2009 who reported that the response to imatinib may be dose and tissue dependent ${ }^{42}$.

In conclusion Appropriate protective measures must be applied with anticancer treatment for improving liver function. This study provide an in -vivo evidence, at light microscopic, of direct chemotherapeutic hepatotoxicity caused by imatinib. Furthermore, this study identified pathological features at structural level, which could be used as the basis for determining the appropriate dose of these drugs to reduce their hepatotoxic effects. Postmarketing experience with drugs such as imatinib, lapatinib and sorafenib suggests that the hepatotoxic safety of all the TKIs requires diligent surveillance.

\section{References}

1. Santos FPS, Kantarjian H, Alfonso Quintás-Cardama A, et al. Evolution of Therapies for Chronic Myelogenous Leukemia Cancer J. 2011;17(6): 465476.

2. Gishizky ML, Johnson-White J, Witte ON. Efficient transplantation of BCR-ABL-induced chronicmyelogenous leukemia-like syndrome in mice. Proc Natl Acad Sci U S A. 1993;90(8):3755-3759.

3. Druker BJ, Guilhot F, O'Brien SG, et al. Five-year follow-up of patients receiving imatinib for chronic myeloid leukemia. N Engl J Med 2006; 355(23):2408-2417. 
4. El-Sayyad H., Ismail M.F., Shalaby F.M et al. Histopathological effects of cisplatin, doxorubicin and 5-flurouracil (5-FU) on the liver of male albino rats. Intern J Biol Sci 2009;5(5):466-473.

5. Deininger M, Buchdunger E, Druker BJ. The development of imatinibas a therapeutic agent for chronic myeloid leukaemia. Blood 2005;105:26402653.

6. Dagher R, Cohen M,Williams G. et al. Approval summary: imatinib mesylate in the treatment of metastatic and / or unresectable malignant gastrointestinal stromal tumours. Clin Can Res 2002;8:3034-3038.

7.Kingham TP, Dematteo RP. Multidisciplinary treatment of gastrointestinal stromal tumors. Surg Clin North Am 2009;89:217-233.

8. Demetri GD, Wang Y, Wehrle E, Racine A, Nikolova Z, Blanke CD, et al. Imatinib plasma levels are correlated with clinical benefit in patients with unresectable/metastatic gastrointestinal stromal tumors. J clin Oncol 2009;27:3141-3147.

9. Buchdunger E, Cioffi CL, Law N. et al. Abl protein tyrosine kinase inhibitor ST1571 inhibits in vitro signal transduction mediated by c-kit and platelet derived growth factor receptors. J Pharmacol ExpTher 2000; 295:139-145.

10. Handolias D, McArthur GA. Imatinib as effective therapy for dermatofibrosarcoma protuberans: proof of concept of the autocrine hypothesis for cancer. Future Oncol. 2008;4:211-217.

11. Haberler C, Gelpi E, Marosi C, et al. Immunohistochemic alanalysis of platelet-derived growth factor receptoralpha, -beta, c-kit, c-abl, and arg proteins in glioblastoma: possible implications for patient selection for imatinib mesylate therapy. J Neuro oncol 2006; 76: 105-109.

12. Leder C, Ortler S, Seggewiss R, Einsele H, Wiendl H. Modulation of T- effect or function by imatinib at the level of cytokine secretion. Exp Hematol 2007;35:1266-1271.

13. Lassila M, Allen TJ, Cao Z, et al. Imatinib attenuates diabetes-associated atherosclerosis. Arterioscler Thromb Vasc Biol 2004; 24:935-942.

14. Gschwind HP, Pfaar U, Waldmeier F, et al. Metabolism and disposition of imatinib in healthyvolunteers. Drug Metab Dispos 2005; 33:1503-1512.

15. Ramalingam $\mathrm{S}$, Lagattuta $\mathrm{TF}$, Egorin MJ, et al.Biliary excretion of imatinib mesylate and itsmetabolite CGP 74588 in humans. Pharmacotherapy 2004;24:1232-1235.

16. Peng B, Lloyd P, Schran H.Clinical pharmacokinetics of imatinib. Clin Pharmacokinet 2005;44:879-894.

17. Pou M, Saval N, Vera M, Saurina A, Solé M,Cervantes F, Botey A. Acute renal failure secondaryto imatinib mesylate treatment in chronic myeloid leukemia. Leuk Lymphoma. 2003;44:1239-1241.

18. Foringer JR, Verami RR, Tjia VM, et al. Acute renal failure to imatinib mesylate treatment in prostate cancer. Ann Pharmacother 2005;39:21362138.

19. Cross TJ, Bagot C, Portmann B, et al. Imatinib mesylate as a cause of acute liver failure. Am J Hematol 2006;81:189-192.

20. Lin NU, Sarantopoulos S, Stone $\mathrm{JR}$, et al. Fatal hepatic necrosis following imatinib mesylate therapy. Blood 2003;102:3455-2456.

21. Thia TJK, Tan HH, Chuah THC, etal. Imatinib mesylate-related fatal acute hepatic failure in a patient with chronic myeloid leukaemia and chronic hepatitis B infection. Singapore Med J 2008;49: e86-e89.

22. Favareto APA, Fernandez CDB, Fossato da Silva DA, et al. Persistent Impairment of Testicular Histology and Sperm Motility in Adult Rats Treated with Cisplatin at Peri-Puberty. 
Basic Clin Pharmacol Toxicol 2011;109:85-96

23. Ilbey YO, Ozbek E, Cekmen M, et al. Protective effect of curcumin in cisplatin-induced oxidative injury in rattestis: mitogen-activated protein kinase and nuclear factor-kappa B signaling pathways. Human Reprod 2009.24(7): 1717-1725.

24. D'Souza UJA. Toxic effects of 5fluorouracil on sperm count in wistar rats. Malaysian $\mathrm{J}$ Med Sci 2003;10(1):43-45.

25. Mohan M, Bhandare S. Protective effect of solanum torvum against testicular toxicity in male wistar rats. Inter $\mathrm{J}$ Pharm and Pharmaceut Sci 2012;4(3):188-192.

26. Kerkela R., Grazette L, Yacobi R, et al. Cardiotoxicity of the cancer therapeutic agent imatinib mesylate. Nature Med 2006;12 (8):908-916.

27. Bachmann K, Pardoe D, White D. Scaling basic toxicokinetic parameters from rat to man. Environ Health Perspect 1996;104:400-407.

28. Yaghmaei P, Parivar K, Gharibi A, et al. The biological effects of imatinib on male fertility of wistar rats. Inter $\mathbf{J}$ Fertil Steril 2009;3(3):135-142.

29. Saad SY, Alkharfy KH, Arafah MM. Cardiotoxic effects of arsenic trioxide/imatinib mesilate combination in rats. JPP 2006,58:1-7

30. Afify M, Mohamed Diaa El-dien Abd Elmaksoud1, Tamer Mosa, Marwa Elshaer. Differential effects of amitriptyline treatment on testicular and liver functions in adult male rats. New York Sci J 2010;3(3)

31. Segara I, Judson JP, Pasupati Th., Nassar I. Histopathological study of the hepatic and renal toxicity associated with the co-administration of Imatinib and Acetaminophen in a preclinical mouse model. Malaysian $\mathrm{J}$ Pathol 2010;32(1):1-11.

32. Kose E, Sapmaz HI, Sarihan E, etal. Beneficial Effects of Montelukast Against Methotrexate-Induced Liver
Toxicity: A Biochemical and Histological Study. The Scientific World Journal. Volume 2012, Article ID 987508, 6 pages. doi: 10.1100/2012/987508.

33. Lim A.YL, Segarra I., Chakravarthi $\mathrm{S}$, Akram S, John P Judson J.P. Histopathology and biochemistry analysis of the interaction between sunitinib and paracetamol in mice. BMC Pharmacol 2010;10:14 .

34. Vardi N, Parlakpinar H, Cetin A, et al. Protective Effect of b-Carotene on Methotrexate-Induced Oxidative Liver Damage. Toxicol Pathol 2010;38:592.

35. Shah R.R., Morganroth J, Shah D.R. Hepatotoxicity of Tyrosine Kinase Inhibitors: Clinical and Regulatory Perspectives. Drug Safety 2013,36( 7 ):491-503.

36. Cohen MH, Williams G, Johnson $\mathrm{JR}$, et al. Approval summary for imatinib mesylate capsules in the treatment of chronic myelogenous leukemia. Clin Can Res 2002;8:935942.

37. Kikuchi S, Muroi K, Takahashi S, et al. Severe hepatitis and complete molecular response caused by imatinib mesylate: possible association of its serum concentration with clinical outcomes. Leuk Lymphoma 2004;45: 2349-2351.

38. Druker BJ, Guilhot F, O'Brien SG, et al. Five year follow-up of patients receiving imatinib for chronic myeloid leukemia. N Engl J Med 2007;356: 2408-2417.

39. Saad SY, Najja TA, Al-Rikabi AC. The preventive role of deferoxamine against acute doxorubicin-induced cardiac, renal and hepatic toxicity in rats. Pharmacol Res 2001;43:211-218.

40. Deepa PR, Varalakshmi P. Protective effect of low molecular weight heparin on oxidative injury and cellular abnormalities in adriamycininduced cardiac and hepatic toxicity. Chem Biol Interact 2003; 146:201-210. 
41. Łubgan D, Marczak A, Walczak $\mathrm{M}$, et al. Pharmacological mechanisms of Doxorubicin activity (DOX)current state of knowledge. Przegl Lek 2006; 63:782-788.

42. Sook Han M., Wook Chung K., G, et al. Imatinib Mesylate Reduces Endoplasmic Reticulum Stress and Induces Remission of Diabetes in $\mathrm{db} / \mathrm{db}$ Mice. Diabetes 2009; 58: 329336.

43. Herman EH, Knapton A, Rosen E, et al. Multifaceted Evaluation of Imatinib-induced Cardiotoxicity in the Rat. Toxicol Pathol 2011;39(7):10911106.

44. Hosseini A, Pakdel FGH, Ahmadi A, et al. Beneficial effects of American ginseng on epididymal sperm analysis in cyclophosmide treated rats. Cell J 2012, 14(2):116-121.

45. David F, Pei-Ra L, Charlotte A, Bruce R. Hepatic indicators of oxidative stress and tissue damage accompanied by systemic inflammation in rats following a 24hour infusion of an unstable lipid emulsion admixture. J Parent Enteral Nutr. 2009; 33(3): 327-335.

46. Aliesa A. Effect of calcium chloride on cyclophosphamide-induced genotoxic and biochemical changes in swiss albino mice. Inter $\mathrm{J}$ Pharmacol 2007;3(6):492-498.
47. Elkiran T, Harputluoglu H, Yasar U, Babaoglu M, Dincel A, Altundag K, Ozisik, Y, Guler N, Bozkurt A. Differential alteration of drug metabolizing enzyme activities after cyclophosphamide/ adriamycin administration in breast cancer patients".Methods Find Exp Clin Pharmacol 2007;29(1):27.

48. Elangovan $\mathrm{S}$, Chidambaram $\mathrm{P}$, Yenjerla M, Palaninathan V. "Mitigation of oxidative stress in cyclophosphamide-challenged hepatic tissue by DL- $\alpha$-lipoic acid". Molecular and Cellular Biochemistry. 2005, 272(1):179-185,

49. Premila A, Indirani K, Preethi k. Alterations in antioxidant enzyme activities and increased oxidative stress in cyclophosphamide- induced hemorrhagic cystitis in the rat. Cancer Therapy 2008,6:563-570.

50. Ahmet K, Reiter J, Turgut T,Lucien C, Sukru O, Dun-Xian T. Melatonin: an established antioxidant worthy of use in clinical trials. Mol Med 2009, 15(2):43-50.

51. Kolli VK, Abraham $P$, Rabi S. Methotrexate-induced nitrosative stress may play a critical role in small intestinal damage in the rat, Archives Toxicol 2008, 82(10):763-770.

52. Farber E. Programmed cell death: Necrosis versus apoptosis. Mod Pathol 1994;7:605-609. 